\title{
Implementation of a Virtual Reality Interface for a Public Library
}

$\begin{array}{ll}\begin{array}{l}\text { Ilya Minyaev } \\ \text { University of Oulu } \\ \text { Oulu, Finland } \\ \text { ilya.minyaev@oulu.fi }\end{array} & \begin{array}{l}\text { Johanna Ylipulli } \\ \text { University of Helsin } \\ \text { University of Oulu } \\ \text { Oulu, Finland } \\ \text { johanna.ylipulli@he }\end{array} \\ \begin{array}{l}\text { Matti Pouke } \\ \text { University of Oulu }\end{array} & \begin{array}{l}\text { Timo Ojala } \\ \text { VTT Technical Research Centre } \\ \text { of Finland }\end{array} \\ \begin{array}{l}\text { Oulu, Finland } \\ \text { Oulu, Finland } \\ \text { matti.pouke@oulu }\end{array}\end{array}$

Permission to make digital or hard copies of part or all of this work for personal or classroom use is granted without fee provided that copies are not made or distributed for profit or commercial advantage and that copies bear this notice and the full citation on the first page. Copyrights for third-party components of this work must be honored. For all other uses, contact the Owner/Author.

MUM'18, November 25-28, 2018, Cairo, Egypt.

Copyright $\odot 2018$ Copyright is held by the owner/author(s)

ACM ISBN 978-1-4503-6594-9/18/11.

https://doi.org/10.1145/3282894.3289718

\begin{abstract}
In this demo paper we describe the development process and technical implementation of an interactive Virtual Reality (VR) application dubbed Virtual Library. The application utilizes consumer VR hardware and Unreal Engine to provide an immersive virtual interface to a physical library and its selected services, as well as browsing of literature content in aesthetic fantasy realms. The prototype is publicly available at the Oulu City Library.
\end{abstract}

\section{Author Keywords}

Digital library services; mirror world; fantasy worlds; Unreal Engine.

\section{ACM Classification Keywords}

H.3.7 [Digital Libraries]: Dissemination.

\section{CCS Concepts}

-Human-centered computing $\rightarrow$ Virtual reality; Participatory design; -Information systems $\rightarrow$ Digital libraries and archives;

\section{Introduction}

In Finland, public libraries are highly popular; they are regarded as important democratic and and non-commercial arenas attracting people from all demographics $[1,6]$. In this paper, we describe the development process and tech- 
Virtual Environments (VEs) contained in the prototype

City Library mirrors the physical Oulu City library and contains an interactive art gallery as well the functionality to search the library database.

Fantasy Village is a naturethemed medieval village that offers fantasy-themed book recommendations.

Future Alley resembles a futuristic city-noir setting that contains book recommendations.

The Study is a cozy fireplace room that contains interactive objects as well as a "magic book" for collaborative writing of stories. nical implementation of an interactive Virtual Reality (VR) application called Virtual Library that is deployed at the Oulu City Library for technology education.

We had three distinct goals in mind when developing the Virtual Library. Firstly, the application was to provide our partner library with means for educating library patrons about novel VR technology and its possibilities - public libraries in Finland have the obligation to support citizens' lifelong learning, including the introduction of new technologies. Secondly, we aimed for digitally complementing existing library services in our partner library, such as its art exhibition. Thirdly, leveraging the immersive capabilities of VR technology, we wanted to introduce new exciting ways to browse literature provided by the partner library. The following sections report the development process and technical implementation of the Virtual Library application introduced in more depth in [4].

\section{Development process}

The primary method for developing the Virtual Library prototype was Participatory Design [5]. We arranged two multistakeholder workshop sessions to create ideas and gather specifications for the application. In addition, the design and development process has entailed numerous meetings where the researchers and library staff have been able to discuss, share ideas and find common goals.

\section{Workshop 1}

The development process for the Virtual Library prototype was commenced by setting up a half-day long workshop, arranged in close cooperation with the Oulu City Library. The goal was to create ideas and preliminary concepts for a Hybrid Library; it is a vision of a future library, where physical reality and library's services are extended and enhanced with VR, augmented reality (AR) and 3D web.
The workshop brought researchers, library staff and library users (35 participants) together to co-create. All the workshop activities were audio and video recorded; after analyzing the collected material with thematic analysis, we made a decicion to concentrate first on VR and develop services and ideas connected to other technologies later. [7]

\section{Workshop 2}

A second multi-stakeholder workshop was set up half a year later, after the material from the first workshop had been analyzed. This time the workshop was more focused as we explored only the possibilities of VR in library context; the goal here was to develop further certain chosen ideas, based on the results of the first workshop, together with the participants (17). For this workshop, we developed a first interactive prototype of the Virtual Library to demonstrate to participants the potential of this particular technology. With the help of the prototype we also wanted to pilot one of the main ideas that was drawn from the first workshop: the virtual representation of the physical library, a mirror world, was complemented with fantastic digital worlds. The idea behind this structure is that literature and other library content can be understood as a portal transporting people into different realities. The activities of the second workshop were also recorded and analyzed with thematic analysis. Overall, the Virtual Library as whole, all its services and features, are based on ideas and suggestions that came repeatedly up in the workshops. We created the concept for Virtual Library after all the research material from the workshops had been analyzed. Further, the concept was presented to the library staff and improved according to their feedback.

\section{System description}

Virtual Library is an interactive game engine application, in which the user can visit a virtual version of the Oulu City Li- 
brary that is augmented with various fantasy layers. While the application contains the functionality for multiplayer as well as both desktop FPS and VR modalities, the demo described in this paper focuses on single-player VR experience.

The VR experience is a room-scale Virtual Reality (VR) application developed especially for the Oculus Rift device and Touch controllers. While using the application, the user can walk within the range of the Oculus optical beacons. The teleportation method that has become common in room scale VR applications is used to move larger distances. This locomotion method was also chosen to reduce Cybersickness experienced by the users [3]. Touch controllers are also used for interaction; the user can point and click various interactive hotspots contained within the environment. In addition, the user can utilize the grabbing metaphor for certain interactions.

The prototype leverages various components from Unrea Engine $^{1}$ to define the application logic, namely GameMode, Pawn, PlayerController, GameState and Alcontroller. The GameMode is used for defining application logic for desktop and VR modes. The PlayerController defines the user's interaction capabilities and maps them into the playe Pawn. Both desktop and VR modes utilize their own Pawns. The GameState component is used for defining player states when the application is being run in the multiplayer mode. The AlController is used to define the behaviour on non-player-controlled pawns that have changing animation states.

The system also contains an external web-server that is used to administer a virtual art exhibition as well as to provide the client application the functionality to browse the li-

\footnotetext{
${ }^{1}$ https://www.unrealengine.com/en-US/blog
}

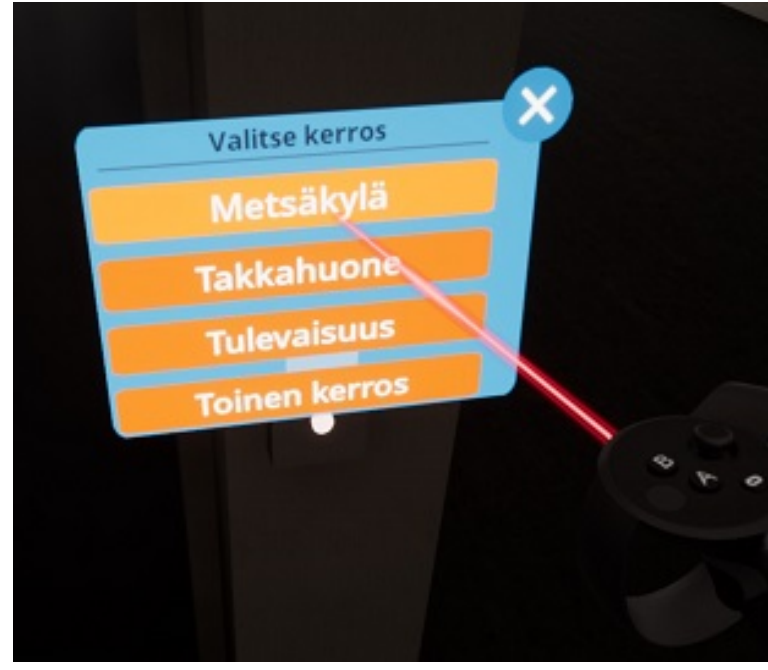

Figure 1: Elevator interface

brary database. In addition, the application contains a builtin database to store textual information needed by some of the services within the application.

The static meshes of the VEs are a combination of selfmodeled, public domain and commercial assets. The starting level, City Library, contains mostly self-modeled assets while the other three VEs utilize assets from various content packages. The humanoid skeletal meshes were created with the Adobe Fuse CC software ${ }^{2}$.

\section{Virtual environments}

The application contains four separate VEs: (levels). The VEs are called City Library, Fantasy Village, Future Alley and Study. The themes for the VEs were chosen according

\footnotetext{
${ }^{2}$ https://www.adobe.com/fi/products/fuse.html
} 


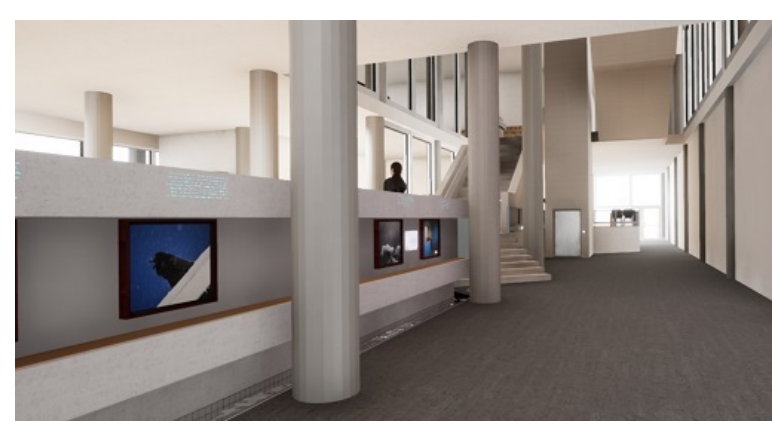

Figure 2: City Library VE

to workshop material analysis. Each VE contains interactive services fitting the overall theme of the level (each service is described in greater detail in the next section).

The application starts from the City Library VE. It represents the bottom two floors of the physical Oulu City library (Fig. 2). It acts as an introductory VE, containing small elements that were chosen among the other three VEs.

The VE contains two interactive services, a functionality to search the actual library database and an interactive art exhibition. From this level the user can move to the three fantasy VEs by stepping into an elevator (Fig. 1).

One of the most recurrent themes within the workshop material was a relaxing forest that the users could visit from the mirror world. The Fantasy Village VE represents a forest containing a lake and a medieval village. The level contains book recommendations selected by library staff and presented both in written and audio format. In this VE, the recommended books are mostly fantasy literature for young adults. The VE utilizes assets from the Unreal Marketplace Advanced Village Pack.

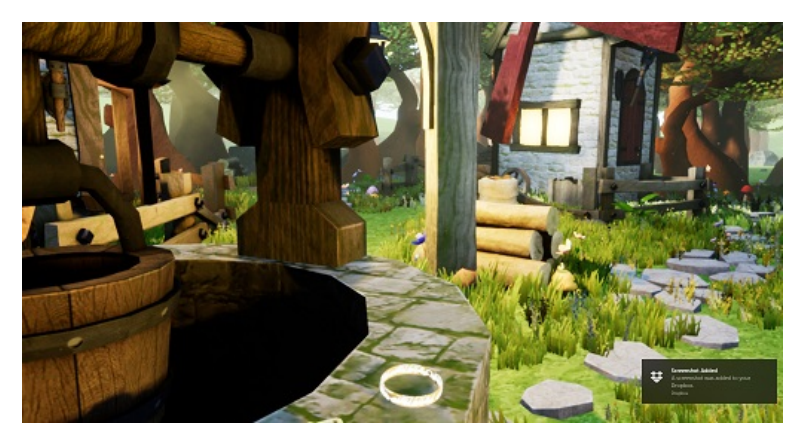

Figure 3: Fantasy Village VE

The Study VE was created to host playful and collaborative activities [1]. Visually, the VE represents a cozy room with wooden furniture and a fireplace. The room contains a large number of interactive objects the user can pick up and play with. The VE also contains an animated cat which responds to user interaction with meowing and purring. The main interactive service of this VE is a 'magic book' which enables collaborative writing of stories.

The Future Alley VE was created to offer book recommendations for sci-fi (and similar) genres. The VE represents a futuristic, somewhat dystopian, urban setting (4. Similarly to the Fantasy Village, book recommendations act as the interactive service for this VE. The VE utilizes assets from the Unreal Engine Marketplace Cyberpunk Alley Storefronts and the Soul City packages.

\section{Interactive Services}

Interactive services are interactive thematic game objects that were placed in each VE. The purpose of these services is to provide the Virtual Library with interactive content. The services were chosen according to the analysis performed 


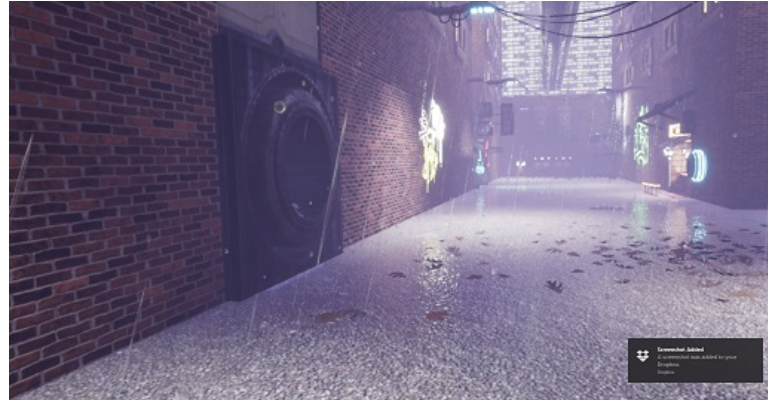

Figure 4: Future Alley VE

on both workshops

\section{Book search}

The City Library level contains a search functionality that allows the user to browse through the library book database. The search functionality is launched from a virtual information desk, which opens up a search window and a virtual keyboard when the user is in proximity. After submitting a search keyword, a 3D carousel-type of a UI is opened; the user can browse through the search results by grabbing the content with his/her controller (see Fig. 5).

By selecting a book from the search results, the user can view additional information, as well as to browse its reviews and recommendations to similar books (provided by Goodreads.com). The user can also use the functionality to find the book's location in the physical library; a virtual route is highlighted to the corresponding shelf location in the Virtual Library. The route finding does not utilize Unreal Engine's built-in pathfinding, but instead calculates the route on the server using Djikstra's algorithm [2]. The drawing of the route utilizes invisible interconnected game objects contained in the VE; the search result returns a list of objects

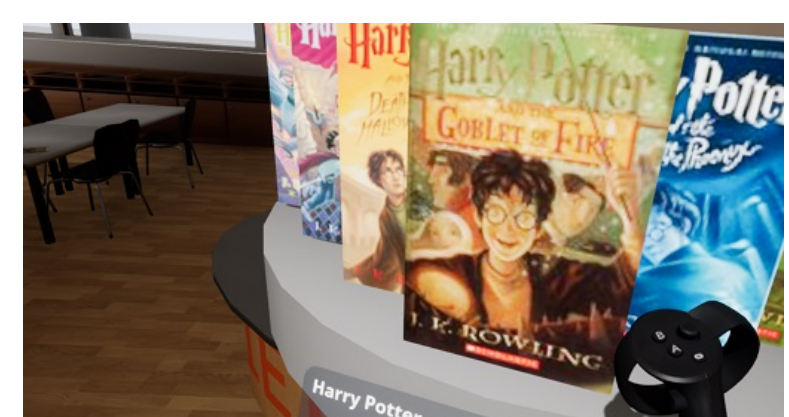

Figure 5: A 3D carousel for browsing the library database

that are highlighted for visualizing the route.

\section{Art Gallery}

The Virtual Art gallery resides in the City Library VE. It contains six interactive frames; each frame can contain one or multiple images. Each frame consists of multiple nested 3D Widgets. When the user is pointing to a frame, the title of the image is highlighted, as well as various functionalities that are coupled with each frame. Interacting with the frame, the user can browse through the images that are stored within. The user can vote each image, however, in the current version the votes cannot be saved. The contents of the frames are stored in the web server; the contents are administered using a separate web user interface.

\section{Book recommendations}

Book recommendations are interactive game objects that contain cover images and introduction texts for various books that were chosen by the library staff. The current book recommendations consist of books for young adults belonging in either (medieval) fantasy or sci-fi genres. The book recommendations for each genre are placed in their corresponding VEs (either Fantasy Village or Future Alley). 


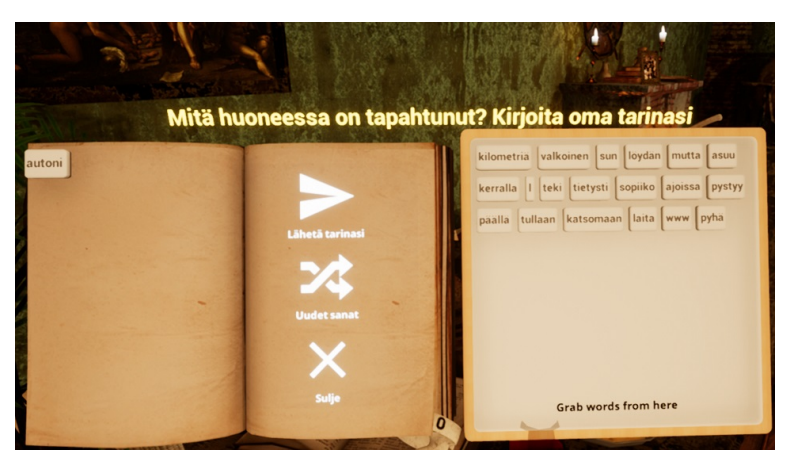

Figure 6: The book object for the Collaborative Storytelling service. The user can write stories by dragging predefined words from right to left.

The textual information (title, introductory text, author, links) is contained in a built-in Unreal Engine specific database. The database imports the book data in .csv format and provides each game object with their corresponding data fields. The book recommendations are visualized as 3D objects that are somehow connected to the theme of the book The objects are scattered across the VEs, so that the users have to search through the VEs to find them. The objects are highlighted when pointed at. Some of the objects also contain audio cues to help finding them.

\section{Collaborative Storytelling}

Collaborative storytelling service is placed in the Study

VE. The game object resembles an open book with floating magic particles. When the user interacts with the book, it opens up an interface consisting of multiple 3D Widgets and game objects for additional interactions (see Fig. 6. It allows users to generate short stories utilizing a "refridgerator magnet" metaphor; the user is provided with a limited selection of words that can be dragged across book pages to form sentences. Each time the book is opened, the selection of words is randomized from 1000 most popular Finnish words. The user can also generate a new set of words. The user can place a words he/she picks after the existing story, between existing words, or use them to replace an existing word. The user can also drag existing words back to the selection. The book generates new lines as necessary according to existing space on a line and the size of the word block.

The stories are saved in the web server. Using the same game object, subsequent users can browse previously saved stories, as well as continue where they left off. The stories can be removed, if necessary, using the web application.

\section{Conclusion}

In this paper, we have described the contents of an interactive demo called the Virtual Library. In the future, we will focus on improving on the current limitations of the system; we are receiving continuous feedback from users as well as the VR instructor operating and overseeing the public setup. In addition, we will focus on gathering and analyzing anonymous quantitative user data from the public deployment at the Oulu City Library.

\section{Acknowledgements}

This work has been supported by the Open Innovation Platforms spearhead project (A70202) and the Open City Model as Open Innovation Platform pilot project (A71143) funded by the ERDF and the City of Oulu under the Six City Strategy program, and the COMBAT project (293389) funded by the Strategic Research Council at the Academy of Finland. We wish to express our gratitude to all study participants and the Oulu City Library. 


\section{REFERENCES}

1. Svanhild Aabø, Ragnar Audunson, and Andreas Vårheim. 2010. How do public libraries function as meeting places? Library \& Information Science Research 32, 1 (2010), 16-26.

2. E. W. Dijkstra. 1959. A Note on Two Problems in Connexion with Graphs. Numer. Math. 1, 1 (Dec. 1959), 269-271. DOI :

http://dx.doi.org/10.1007/BF01386390

3. Gerard Llorach, Alun Evans, and Josep Blat. 2014. Simulator sickness and presence using HMDs:

comparing use of a game controller and a position estimation system. In Proceedings of the 20th ACM Symposium on Virtual Reality Software and Technology. ACM, 137-140.

4. Matti Pouke, Johanna Ylipulli, Ilya Minyaev, Minna Pakanen, Paula Alavesa, Toni Alatalo, and Timo Ojala. 2018. Virtual Library - Blending Mirror and Fantasy
Layers into a VR Interface for a Public Library. In Accepted to the 17th International Conference on Mobile and Ubiquitous Multimedia.

5. Jesper Simonsen and Toni Robertson. 2012. Routledge international handbook of participatory design. Routledge. 86-116 pages.

6. Pertti Vakkari, Svanhild Aabø, Ragnar Audunson, Frank Huysmans, and Marjolein Oomes. 2014. Perceived outcomes of public libraries in Finland, Norway and the Netherlands. Journal of Documentation 70, 5 (2014), 927-944.

7. Johanna Ylipulli, Anna Luusua, and Timo Ojala. 2017. On Creative Metaphors in Technology Design: Case Magic. In Proceedings of the 8th International Conference on Communities and Technologies. ACM, 280-289. 